Marquette University

e-Publications@Marquette

Exercise Science Faculty Research and Publications

Exercise Science, Department of

$1-1-2011$

\title{
Pain Perception after Isometric Exercise in Women with Fibromyalgia
}

Marie K. Hoeger Bement

Marquette University, mariehoeger.bement@marquette.edu

Andy Weyer

Marquette University

Sarah Hartley

Marquette University

Breanna Drewek

Marquette University

April Harkins

Marquette University, april.harkins@marquette.edu

See next page for additional authors

Accepted version. Archives of Physical Medicine and Rehabilitation, Vol. 92, No. 1 (January 2011), DOI: 10.1016/j.apmr.2010.10.006. (C) 2011 Elsevier (WB Saunders). Used with permission. 
Authors

Marie K. Hoeger Bement, Andy Weyer, Sarah Hartley, Breanna Drewek, April Harkins, and Sandra K. Hunter 


\title{
Pain Perception after Isometric Exercise in Women with Fibromyalgia
}

\author{
Marie K. Hoeger Bement \\ Department of Physical Therapy, Marquette University \\ Milwaukee, WI \\ Andy Weyer \\ Department of Physical Therapy, Marquette University \\ Milwaukee, WI \\ Sarah Hartley \\ Department of Physical Therapy, Marquette University \\ Milwaukee, WI \\ Breanna Drewek \\ Department of Physical Therapy, Marquette University \\ Milwaukee, WI \\ April L. Harkins \\ Clinical Laboratory Science, Marquette University \\ Milwaukee, WI \\ Sandra K. Hunter \\ Department of Physical Therapy, Marquette University \\ Milwaukee, WI
}


NOT THE PUBLISHED VERSION; this is the author's final, peer-reviewed manuscript. The published version may be accessed by following the link in the citation at the bottom of the page.
Abstract
Objective: The purpose of this study was to identify exercise protocols incorporating isometric contractions that provide pain relief in women with fibromyalgia.
Design: A before-after trial.
Setting: A physical therapy department in an academic setting.
Participants: Fifteen women (mean \pm SD, $52 \pm 11 \mathrm{y}$ ) with fibromyalgia.
Interventions: Subjects completed 4 sessions: 1 familiarization and 3
experimental. The following randomized experimental sessions involved the performance of isometric contractions with the elbow flexor muscles that varied in intensity and duration: (1) 3 maximal voluntary contractions (MVCs), (2) 25\% MVC held to task failure, and (3) $25 \%$ MVC held for 2 minutes.

Main Outcome Measures: Experimental pain (pain threshold and pain rating), Fibromyalgia Impact Questionnaire, and fibromyalgia pain intensity (visual analog scale).

Results: After all 3 isometric contractions, there was considerable variability between subjects in the pain response. Based on the changes in experimental pain, subjects were divided into 3 groups (increase, decrease, no change in pain). Multiple regression analysis revealed that age, baseline experimental pain, and change in fibromyalgia pain intensity were significant predictors of the experimental pain response after the isometric contractions.

Conclusions: We identified subgroups of women with fibromyalgia based on how they perceived pain after isometric contractions. The greatest pain relief for women with fibromyalgia occurred at a younger age and in women with the greatest experimental pain before exercise. Additionally, we established a link between experimental and clinical pain relief after the performance of isometric contractions.

Fibromyalgia is a disorder that is characterized by chronic widespread pain and tenderness with palpation. The prevalence of fibromyalgia is estimated to be as high as $5 \%$ of the general population, with the majority of persons being women. ${ }^{1}$ The management of fibromyalgia is difficult because many patients do not respond to treatment. For example, only $30 \%$ to $50 \%$ of patients experience significant improvement with medication therapy, ${ }^{2}$ indicating the need to identify alternative therapies for pain relief.

Exercise is one of the few therapies that may improve fibromyalgia symptoms. ${ }^{3,4}$ The majority of the exercise studies ${ }^{3,5-7}$ have focused on aerobic activity leading to improvements in pain, physical function, fatigue, mood, and self-efficacy. Understanding the

Archives of Physical Medicine and Rehabilitation, Vol. 92, No. 1 (January 2011): pg. 89-95. DOI. This article is (C) Elsevier (WB Saunders) and permission has been granted for this version to appear in e-Publications@Marquette. Elsevier (WB Saunders) does not grant permission for this article to be further copied/distributed or hosted elsewhere without the express permission from Elsevier (WB Saunders). 
role and potential benefit of isometric contractions in managing pain with fibromyalgia is important because even patients with limited mobility can perform an isometric contraction. Therefore, there is significant potential for self-management of fibromyalgia pain symptoms by using exercise treatments incorporating isometric contractions.

In healthy adults, both low- and high-intensity isometric contractions produce significant pain relief. ${ }^{8}$ The dosage of isometric contractions to produce pain relief in persons with fibromyalgia is not known. Thus, the primary purpose of this study was to identify effective exercise protocols incorporating isometric contractions by measuring the pain response to various intensities and durations of isometric exercise in women with fibromyalgia.

A secondary purpose was to explore potential mechanisms for exercise-induced changes in pain perception in persons with fibromyalgia. As an index of HPA activity, we measured salivary cortisol levels before and after exercise to understand the role of the HPA axis in modulating the pain response. ${ }^{9}$

\section{Methods}

\section{Subjects}

Fifteen women (mean $\pm S D, 52 \pm 11 y$; range, 19-64y) diagnosed with fibromyalgia completed this study. Subjects were screened for known cardiopulmonary and neurologic problems. Informed consent was acquired before the start of the study, and the protocol was approved by the Institutional Review Board.

\section{General Experimental Protocol}

Subjects completed 4 sessions: 1 familiarization session and 3 experimental sessions. During the familiarization session, experimental pain was measured by using a pressure pain device before and after 30 minutes of quiet rest. Additional measurements included state and trait anxiety ${ }^{10,11}$ and clinical pain assessments using the FIQ, ${ }^{12,13}$ the McGill Pain (shortform) Questionnaire, ${ }^{14}$ and a VAS to measure fibromyalgia pain intensity. Three MVCs were performed at the end of the familiarization session to determine the appropriate target forces for the experimental sessions. (WB Saunders) and permission has been granted for this version to appear in e-Publications@Marquette. Elsevier (WB Saunders) does not grant permission for this article to be further copied/distributed or hosted elsewhere without the express permission from Elsevier (WB Saunders). 
During the following 3 experimental sessions, pain perception was measured before and after isometric contractions that varied in intensity and duration: 25FAIL, 25TIME, and 3 MVCs (MVC session). The isometric contractions were performed during separate randomized sessions, with approximately 1 week between sessions. Heart rate, blood pressure, and the rate of perceived exertion were monitored during the submaximal isometric contractions. Subjects completed the FIQ, the McGill Pain Questionnaire (short-form), and the state anxiety form at the beginning of each session. State anxiety was also assessed after each experimental pain assessment. Fibromyalgia pain intensity measured with a VAS was measured throughout each session at the following time points: start of the experiment, after the first pain test, immediately after the second pain test (and exercise), and 20 minutes after the second pain test.

\section{Measurement of Force during Isometric Contractions}

Subjects performed isometric contractions with the elbow flexor muscles of the left arm while seated. $8,15,16$ The elbow joint was flexed to $90^{\circ}$, and the hand and forearm were placed midway between pronation and supination in a modified wrist-hand- thumb orthesis. ${ }^{a}$ The forces extended by the wrist in the vertical direction were measured with a force transducer ${ }^{\mathrm{b}}$ and recorded online by using a Power 1401 A-D converter and Spike2 software. ${ }^{c}$

\section{Sustained Submaximal Isometric Contraction}

During the submaximal isometric contractions (25FAIL and 25TIME), each subject was required to match the vertical target force as displayed on the monitor. Task failure was determined as the time the force declined by $10 \%$ of the target value for 3 of 5 consecutive seconds.

\section{Experimental Pain}

A pressure pain device was used to measure pain perception before and after exercise. ${ }^{8,15,16} \mathrm{~A} 100$-g mass was applied to a secondclass lever at a distance from the axis that was equivalent to a $0.75-\mathrm{kg}$ mass on the finger. The force at the finger was applied through a Lucite edged and placed on the right index for 2 minutes. Subjects were instructed to say "pain" when they first felt pain (ie, pain threshold), and pain ratings were reported every 20 seconds using a 0

Archives of Physical Medicine and Rehabilitation, Vol. 92, No. 1 (January 2011): pg. 89-95. DOI. This article is @ Elsevier (WB Saunders) and permission has been granted for this version to appear in e-Publications@Marquette. Elsevier (WB Saunders) does not grant permission for this article to be further copied/distributed or hosted elsewhere without the express permission from Elsevier (WB Saunders). 
to 10 scale. The scale had the following terminology: 0 , no pain; 5 , moderate pain; and 10, worst pain. ${ }^{17}$ We previously established the reliability of this device. ${ }^{8}$

\section{Cortisol}

All experiments were conducted in the afternoon when the cortisol levels were near their diurnal trough. ${ }^{18}$ Salivary cortisol was collected upon entering the laboratory and 10 and 20 minutes after the first and second pain measurement. Cortisol levels were quantified using an enzymatic immunosolvent assay. ${ }^{\mathrm{e}}$ Our intra- and interassay coefficients of variation were within standard precision levels per the recommendations of the manufacturer.

\section{Statistical Analysis}

Data are reported as mean \pm SD within the text and displayed as mean $\pm \mathrm{SE}$ in the figures. For each exercise session, repeatedmeasures analysis of variance was used to compare the following variables across trial and/or time: pain threshold, pain rating, fibromyalgia pain intensity, state anxiety, cortisol levels, MAP, and heart rate. Because the pain response varied considerably among the fibromyalgia subjects, the data were analyzed with the betweensubjects factor for pain response (increase, decrease, and no change). Pearson correlations were calculated to determine associations between dependent variables. Stepwise multiple regression was used to analyze the contribution of several variables to the exercise-induced change in pain threshold and pain ratings across all 3 exercise sessions that were pooled together. Only predictors that had significant partial effects were reported for the final regression model. A $P$ value $\leq .05$ was used for statistical significance.

\section{Results}

\section{Familiarization Session}

Pain thresholds and pain ratings remained unchanged after 30 minutes of quiet rest ( $P=.86$ and .66 , respectively). State anxiety and pain intensity assessed from the "current fibromyalgia pain" VAS did not change after the first or second pain test $(P=.99$ and .90 , respectively). Furthermore, state anxiety was not correlated with any of the experimental or clinical pain measures. 
NOT THE PUBLISHED VERSION; this is the author's final, peer-reviewed manuscript. The published version may be accessed by following the link in the citation at the bottom of the page.

\section{Pain Perception}

\section{Experimental Pain}

Pain threshold did not change after exercise for any of the exercise sessions (trial effect: 25FAIL, $P=.22$ [fig 1A]; 25TIME, $P=.25$ [fig 2A]; MVCs, $P=.77$ [fig $3 \mathrm{~A}]$ ). Similarly, pain ratings did not change for any of the exercise sessions (trial effect: 25FAIL, $P=.92$ [fig 1B]; 25TIME, $P=.40$ [fig 2B]; MVCs, $P=.28$ [fig 3B]). There was, however, substantial variability between subjects in the exercise-induced pain response for each session. Based on the pain response, subjects were divided into 3 groups (decrease, increase, no change in pain) by using criteria for pain subgroups that we established previously. ${ }^{19}$ The decreased pain group reported an increase in pain threshold $\geq 10$ seconds and/or a decrease in pain ratings by $\geq 2$ for 2 consecutive time points during the 2-minute pain pressure test. The increased pain group reported a decrease in pain threshold $\geq 10$ seconds and/or an increase in pain ratings by greater than or equal to 2 for 2 consecutive time points. The no change in pain group experienced a less than 10second change in pain threshold and a less than 2 change in pain ratings for 2 consecutive time points. After the submaximal contraction held until task failure (25FAIL), there was an interaction between trial and pain response (decreased pain group $[n=5]$, increased pain group $[\mathrm{n}=5]$, no change in pain group $[\mathrm{n}=5])$ for both pain ratings $(P=.007)$ (fig 1D, F, H) and pain threshold ( $P=.01$ ) (fig 1C, E, G). For 25TIME, there was a trial and pain response interaction (decreased pain group $[\mathrm{n}=2]$, increased pain group $[\mathrm{n}=8]$, no change in pain group $[\mathrm{n}=5]$ ) for the pain ratings $(P=.02)$ (fig $2 \mathrm{D}, \mathrm{F}, \mathrm{H})$ but not for the pain threshold $(P=.07$ ) (fig 2C, E, G). For the MVC exercise session, there was an interaction between trial and pain response (decreased pain group $[\mathrm{n}=5]$, increased pain group $[\mathrm{n}=5]$, no change in pain group $[\mathrm{n}=5]$ ) for both pain ratings $(P=.0001)$ (fig 3D, F, H) and pain threshold ( $P=.001$ ) (fig 3C, E, G).

\section{Clinical Pain}

Fibromyalgia pain intensity measured with the VAS did not change over time when analyzing the group data (time: 25FAIL, $P=.08 ; 25 T I M E, P=.31 ;$ MVCs, $P=.45)$. For VAS, there was no interaction between pain response and time for the submaximal contraction held for 2 minutes or the 3 MVCs (response $\times$ time, $P=.39$ and .42 , respectively). However, there was an interaction for VAS

Archives of Physical Medicine and Rehabilitation, Vol. 92, No. 1 (January 2011): pg. 89-95. DOI. This article is (C) Elsevier (WB Saunders) and permission has been granted for this version to appear in e-Publications@Marquette. Elsevier (WB Saunders) does not grant permission for this article to be further copied/distributed or hosted elsewhere without the express permission from Elsevier (WB Saunders). 
between pain response and time for the submaximal contraction held until task failure $(P=.02)$. Thus, after fatiguing isometric contractions, the pain subgroups were similar for experimental and clinical pain.

\section{Time to Task Failure}

Women with fibromyalgia sustained the 25\% MVC held until task failure for $502 \pm 262$ seconds. Five subjects (33\%) requested to stop the exercise session despite minimal indications of fatigue associated with force decline. The RPEs of these 5 subjects were all at a maximal of 10 when they requested to cease the contraction. There was an association between the exercise-induced change in fibromyalgia pain intensity and the time to task to failure $(r=.54$, $P=.04$ ) such that those subjects who had the longest time to failure experienced an increase in pain after exercise.

\section{Anxiety}

State anxiety levels did not change during any of the exercise sessions (time effect: $P>.05$ ). Furthermore, there was no interaction between pain response and time for state anxiety $(P>.05)$.

\section{Cortisol}

Salivary cortisol levels remain unchanged over time during each of the exercise sessions $(P>.05)$, indicating that there was no measurable change in cortisol after the pressure pain test or the performance of isometric contractions. There was no interaction for cortisol between the pain response and time $(P>.05)$.

\section{MAP, Heart Rate, and RPE during the Submaximal Sustained Contractions}

During the submaximal contraction held until task failure (25FAIL), there was a progressive increase in MAP $(P<.0001)$, heart rate $(P=.001)$, and RPE $(P<.0001)$. There was no interaction between pain response and time for MAP, heart rate, or RPE $(P>.05)$, indicating the different pain response groups responded similarly during the fatiguing contraction for these measures.

During 25TIME, there was an increase in MAP $(P<.0001)$ and RPE $(P<.0001)$ although heart rate showed no significant increase 
NOT THE PUBLISHED VERSION; this is the author's final, peer-reviewed manuscript. The published version may be accessed by following the link in the citation at the bottom of the page.

$(P=.27)$. There was no interaction between pain response and time for MAP, heart rate, or RPE $(P>.05)$.

\section{Stepwise Multiple Regression Analysis}

Stepwise regression analysis indicated that age and baseline pain threshold were the most significant predictors for the exerciseinduced change in pain threshold when all 3 sessions were entered into 1 regression analysis. Together these 2 variables explained 32\% ( $\left.r=.56, r^{2}=.32, P=.001\right)$ of the variance in the pain threshold changes after exercise. These results indicate that younger women with fibromyalgia were more likely to experience pain relief after isometric exercise than older women. Also, women with lower baseline pain thresholds were more likely to experience pain relief than those with higher pain thresholds.

For changes in pain ratings, regression analysis showed that baseline pain threshold and change in fibromyalgia pain intensity were the 2 significant predictors, which accounted for $31 \%\left(r=.56, r^{2}=.31\right.$, $P=.001$ ) of the variance. These results indicate that greater relief in experimental pain results in greater attenuation of fibromyalgia pain intensity.

\section{Discussion}

The main purpose of this study was to identify effective isometric contraction intensities and durations that elicit exerciseinduced hypoalgesia in women with fibromyalgia. We first established that the application of the experimental pain test did not result in an increase in experimental pain, clinical pain, or state anxiety in women with fibromyalgia (familiarization session). These results show that any changes in pain reports in the subsequent exercise sessions were because of the exercise intervention and not the methods and execution of the pain test.

After the exercise sessions, there was no change in the pain response when analyzing the group of fibromyalgia women together regardless of the intensity or duration of the isometric contraction. However, there was considerable variability between subjects in that an equal number of subjects experienced exercise-induced increases, decreases, and no changes in pain after the isometric task held until task failure and the 3 MVC sessions. Other research studies ${ }^{20-22}$ have also shown mixed pain responses after isometric exercise in

Archives of Physical Medicine and Rehabilitation, Vol. 92, No. 1 (January 2011): pg. 89-95. DOI. This article is (C) Elsevier (WB Saunders) and permission has been granted for this version to appear in e-Publications@Marquette. Elsevier (WB Saunders) does not grant permission for this article to be further copied/distributed or hosted elsewhere without the express permission from Elsevier (WB Saunders). 
fibromyalgia patients. Therefore, the assumption that patients with chronic pain are homogenous may explain the deficit in successful treatment options for some patients. ${ }^{23}$

Multiple regression analysis revealed that one of the main predictors of the change in pain threshold was the age of the woman. We found that younger women with fibromyalgia were more likely to experience pain relief than older women. Consistent with our results, for studies in which there was an exercise-induced increase in pain, the fibromyalgia subjects had an average age of 46 and 48 years old, ${ }^{21,22}$ whereas there was no change or decrease in pain for a study in which the subjects' average age was 39 years. ${ }^{20}$ The influence of age on the exercise response has important implications in the management of fibromyalgia because the prevalence of fibromyalgia increases with age. ${ }^{1}$

This study also established that baseline pain threshold predicted exercise-induced changes in both pain threshold and pain ratings. Specifically, persons with lower pain thresholds during the first experimental pain test were more likely to experience a postexercise decrease in pain compared with subjects who had higher baseline pain thresholds. Interestingly, tenderness with evoked-pain testing has been shown to be an important factor in determining subgroups. ${ }^{24}$ However, our study is the first to show that baseline levels of experimental pain can predict pain relief and the effectiveness of exercise. One explanation for baseline levels as a predictor is that those subjects who experienced the greatest baseline pain (before exercise) may have more pain during the exercise intervention. Thus, exercise would act as a counterirritant (ie, activation of nociceptors produce an endogenous analgesic response), resulting in greater pain relief for these persons after exercise compared with those who experienced less baseline pain. ${ }^{25}$

Another predictor for exercise-induced changes in pain was the change in fibromyalgia pain intensity. Those subjects who had the greatest experimental pain relief also had the greatest decrease in fibromyalgia pain intensity. Thus, the experimental and clinical pain responses were similar in direction and magnitude after isometric exercise. Fibromyalgia pain intensity (VAS) was also associated with time to failure of the submaximal contraction. Those subjects who maintained the contraction for a longer duration were more likely to experience an increase in pain compared with subjects who maintained

Archives of Physical Medicine and Rehabilitation, Vol. 92, No. 1 (January 2011): pg. 89-95. DOI. This article is (C) Elsevier (WB Saunders) and permission has been granted for this version to appear in e-Publications@Marquette. Elsevier (WB Saunders) does not grant permission for this article to be further copied/distributed or hosted elsewhere without the express permission from Elsevier (WB Saunders). 
the contraction for a shorter duration. Furthermore, the time to failure was influenced by a subset of subjects (33\% of the subjects) who asked to stop the submaximal contraction before the force criteria for ending the task were reached. Previous studies $22,26-29$ have shown that persons with fibromyalgia report greater levels of perceived effort and higher pain levels for both static and dynamic contractions compared with healthy controls. This exertional pain may be related to exerciseinduced muscle ischemia and sensitization of the peripheral nervous system. ${ }^{21,30}$ Because we did not assess pain during the exercise sessions in this study, whether subjects requested to stop because of exercise-induced increases in pain cannot be determined.

To determine potential mechanisms responsible for exerciseinduced changes in pain perception, activation of the HPA axis was assessed by measuring salivary cortisol levels. However, an acute bout of isometric contractions, regardless of intensity or duration, did not change cortisol levels. These results are similar to our previous study in healthy young women. ${ }^{15}$ Several other studies ${ }^{28,31-34}$ have assessed the effect of various exercise protocols on cortisol levels in fibromyalgia subjects with a wide range of results. Consequently, changes in cortisol levels after an acute bout of exercise do not appear to mediate exercise-induced hypoalgesia.

\section{Study Limitations}

The main limitation of this study was that pain perception was not measured during the exercise session. Thus, we do not know if persons who requested to stop the fatiguing exercise session did so due to pain. Another related issue is that we do not know if exercise acted as a counterirritant, therefore explaining the hypoalgesia for some subjects. Future studies warrant examining pain during exercise in patients with fibromyalgia.

\section{Conclusions}

There is considerable variability in pain reports of women with fibromyalgia after the performance of isometric contractions. The pain response was predicted by age, baseline experimental pain measures, and changes in fibromyalgia pain intensity. Additional research is needed to further characterize the subgroups of the pain response to exercise and to determine if these subgroups persist with long-term training programs. Our findings potentially have important clinical (WB Saunders) and permission has been granted for this version to appear in e-Publications@Marquette. Elsevier (WB Saunders) does not grant permission for this article to be further copied/distributed or hosted elsewhere without the express permission from Elsevier (WB Saunders). 
implications for patients with fibromyalgia. First, we established that clinical and experimental pain relief can be harnessed at least in the short-term from static contractions in some patients with fibromyalgia, thereby establishing the important link between clinical and experimental pain. Furthermore, our results show that women with fibromyalgia who experience substantial pain perception before exercise may gain the greatest pain relief from isometric contractions.

\section{References}

1. Neumann L, Buskila D. Epidemiology of fibromyalgia. Curr Pain Headache Rep 2003;7:362-8.

2. Goldenberg DL. Fibromyalgia syndrome a decade later: what have we learned? Arch Intern Med 1999;159:777-85.

3. Busch AJ, Barber KA, Overend TJ, Peloso PM, Schachter CL. Exercise for treating fibromyalgia syndrome. Cochrane Database Syst Rev 2007;4:CD003786.

4. Goldenberg DL, Burckhardt C, Crofford L. Management of fibromyalgia syndrome. JAMA 2004;292:2388-95.

5. Brosseau L, Wells GA, Tugwell $P$, et al. Ottawa Panel evidence- based clinical practice guidelines for strengthening exercises in the management of fibromyalgia: part 2. Phys Ther 2008;88:873-86.

6. Busch AJ, Schachter CL, Overend TJ, Peloso PM, Barber KA. Exercise for fibromyalgia: a systematic review. J Rheumatol 2008; 35:1130-44.

7. Gowans $S E$, deHueck $A$. Effectiveness of exercise in management of fibromyalgia. Curr Opin Rheumatol 2004;16:138-42.

8. Hoeger Bement MK, Dicapo J, Rasiarmos R, Hunter SK. Dose response of isometric contractions on pain perception in healthy adults. Med Sci Sports Exerc 2008; $40: 1880-9$.

9. Lundy-Ekman L. Neuroscience fundamentals for rehabilitation. 3rd ed. St. Louis: Saunders; 2007.

10. Barnes LLB, Harp D, Jung WS. Reliability generalization of scores on the Spielberger state-trait anxiety inventory. Educ Psychol Meas 2002;62:603-18.

11. Spielberg CD. Manual for the state-trait anxiety inventory. Palo Alto, CA: Consulting Psychologists Pr; 1983.

12. Bennett R. The Fibromyalgia Impact Questionnaire (FIQ): a review of its development, current version, operating characteristics and uses. Clin Exp Rheumatol 2005;23(5 Suppl 39):S154-62.

13. Burckhardt CS, Clark SR, Bennett RM. The fibromyalgia impact questionnaire: development and validation. J Rheumatol 1991;18: 728-33.

Archives of Physical Medicine and Rehabilitation, Vol. 92, No. 1 (January 2011): pg. 89-95. DOI. This article is (C) Elsevier (WB Saunders) and permission has been granted for this version to appear in e-Publications@Marquette. Elsevier (WB Saunders) does not grant permission for this article to be further copied/distributed or hosted elsewhere without the express permission from Elsevier (WB Saunders). 
NOT THE PUBLISHED VERSION; this is the author's final, peer-reviewed manuscript. The published version may be

accessed by following the link in the citation at the bottom of the page.

14. Melzack R. The short-form McGill Pain Questionnaire. Pain 1987;30:1917.

15. Hoeger Bement MK, Rasiarmos RL, DiCapo JM, et al. The role of the menstrual cycle phase in pain perception before and after an isometric fatiguing contraction. Eur J Appl Physiol 2009;106:105-12.

16. Hoeger Bement MK, Weyer A, Hartley S, Yoon T, Hunter SK. Fatiguing exercise attenuates pain-induced corticomotor excitability. Neurosci Lett 2009;452:209-13.

17. McCaffery M, Pasero M. Pain: Clinical manual. 2nd ed. St. Louis: Mosby; 1999.

18. Schmidt-Reinwald A, Pruessner JC, Hellhammer DH, et al. The cortisol response to awakening in relation to different challenge tests and a 12-hour cortisol rhythm. Life Sci 1999;64:1653-60.

19. Hoeger Bement MK, Weyer A, Keller A, Harkins A, Hunter SK. Anxiety and stress can predict pain perception following a cognitive stress. Physiol Behav 2010;101:87-92.

20. Kadetoff $D$, Kosek $E$. The effects of static muscular contraction on blood pressure, heart rate, pain ratings and pressure pain thresholds in healthy individuals and patients with fibromyalgia. Eur J Pain 2007; 11:39-47.

21. Kosek E, Ekholm J, Hansson P. Modulation of pressure pain thresholds during and following isometric contraction in patients with fibromyalgia and in healthy controls. Pain 1996;64:415-23.

22. Staud R, Robinson ME, Price DD. Isometric exercise has opposite effects on central pain mechanisms in fibromyalgia patients compared to normal controls. Pain 2005;118:176-84.

23. Turk DC. The potential of treatment matching for subgroups of patients with chronic pain: lumping versus splitting. Clin J Pain 2005;21:44-55; discussion 69-72.

24. Giesecke T, Williams DA, Harris RE, et al. Subgrouping of fibromyalgia patients on the basis of pressure-pain thresholds and psychological factors. Arthritis Rheum 2003;48:2916-22.

25. Willer JC, Roby A, Le Bars D. Psychophysical and electrophysiological approaches to the pain-relieving effects of heterotopic nociceptive stimuli. Brain 1984;107:1095-112.

26. Mengshoel AM, Vollestad NK, Forre O. Pain and fatigue induced by exercise in fibromyalgia patients and sedentary healthy subjects. Clin Exp Rheumatol 1995;13:477-82.

27. Miller TA, Allen GM, Gandevia SC. Muscle force, perceived effort, and voluntary activation of the elbow flexors assessed with sensitive twitch interpolation in fibromyalgia. J Rheumatol 1996; 23:1621-7.

Archives of Physical Medicine and Rehabilitation, Vol. 92, No. 1 (January 2011): pg. 89-95. DOI. This article is (C) Elsevier (WB Saunders) and permission has been granted for this version to appear in e-Publications@Marquette. Elsevier (WB Saunders) does not grant permission for this article to be further copied/distributed or hosted elsewhere without the express permission from Elsevier (WB Saunders). 
28. Giske L, Vollestad NK, Mengshoel AM, Jensen J, Knardahl S, Roe C. Attenuated adrenergic responses to exercise in women with fibromyalgia-a controlled study. Eur J Pain 2008;12:351-60.

29. Maquet D, Croisier JL, Renard C, Crielaard JM. Muscle performance in patients with fibromyalgia. Joint Bone Spine 2002;69: 293-9.

30. Jones KD, Liptan GL. Exercise interventions in fibromyalgia: clinical applications from the evidence. Rheum Dis Clin North Am 2009;35:373-91.

31. Gursel Y, Ergin S, Ulus Y, Erdogan MF, Yalcin P, Evcik D. Hormonal responses to exercise stress test in patients with fibromyalgia syndrome. Clin Rheumatol 2001;20:401-5.

32. Paiva ES, Deodhar A, Jones KD, Bennett R. Impaired growth hormone secretion in fibromyalgia patients: evidence for augmented hypothalamic somatostatin tone. Arthritis Rheum 2002; 46:1344-50.

33. van Denderen JC, Boersma JW, Zeinstra P, Hollander AP, van Neerbos BR. Physiological effects of exhaustive physical exercise in primary fibromyalgia syndrome (PFS): is PFS a disorder of neuroendocrine reactivity? Scand J Rheumatol 1992; 21:35-7.

34. Valkeinen $\mathrm{H}$, Hakkinen $\mathrm{K}$, Pakarinen $\mathrm{A}$, et al. Muscle hypertrophy, strength development, and serum hormones during strength training in elderly women with fibromyalgia. Scand J Rheumatol 2005;34:309-14.

\section{Suppliers}

a. Orthomerica, 505 31st Street, Newport Beach, CA 92663-3805.

b. JR-3 Force-Moment Sensor, JR-3 Inc., 22 Harter Avenue, Woodland, CA 95776.

c. Cambridge Electronics Design, 4 The Science Park, Milton Rd, Cambridge CB4 OFE, UK.

d. $\quad$ Romus Inc., 23W701 Maple Ave, Roselle, IL 60172.

e. Salimetrics LLC, 101 Innovation Blvd \# 302, State College, PA 16803-6605.

Archives of Physical Medicine and Rehabilitation, Vol. 92, No. 1 (January 2011): pg. 89-95. DOI. This article is (C) Elsevier (WB Saunders) and permission has been granted for this version to appear in e-Publications@Marquette. Elsevier (WB Saunders) does not grant permission for this article to be further copied/distributed or hosted elsewhere without the express permission from Elsevier (WB Saunders). 


\section{Appendix}

Fig. 1
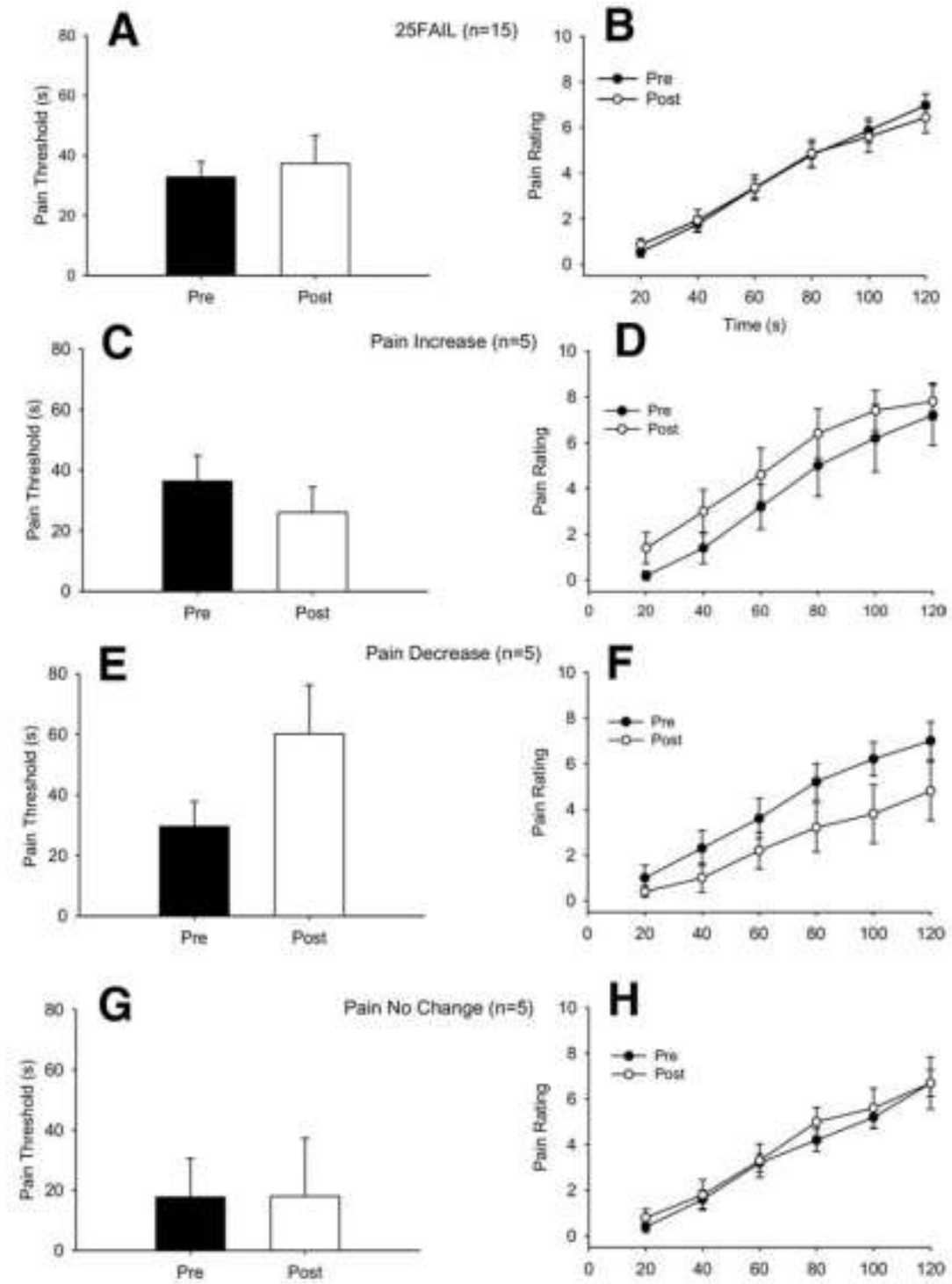

(A) Pain threshold and (B) pain ratings before (pre) and after (post) 25FAIL. There was no significant difference in pain threshold or pain ratings after the sustained contraction $(P>.05)$. Based on the pain response, the subjects were divided into 3 groups (pain increase $[C, D]$, pain decrease $[E, F]$, and no change in pain $[\mathrm{G}, \mathrm{H}])$. There was a significant interaction between trial and pain response for both pain threshold and pain ratings $(P<.05)$. Data are represented as the average \pm standard error of the mean.

Archives of Physical Medicine and Rehabilitation, Vol. 92, No. 1 (January 2011): pg. 89-95. DOI. This article is (C) Elsevier (WB Saunders) and permission has been granted for this version to appear in e-Publications@Marquette. Elsevier (WB Saunders) does not grant permission for this article to be further copied/distributed or hosted elsewhere without the express permission from Elsevier (WB Saunders). 
Fig. 2
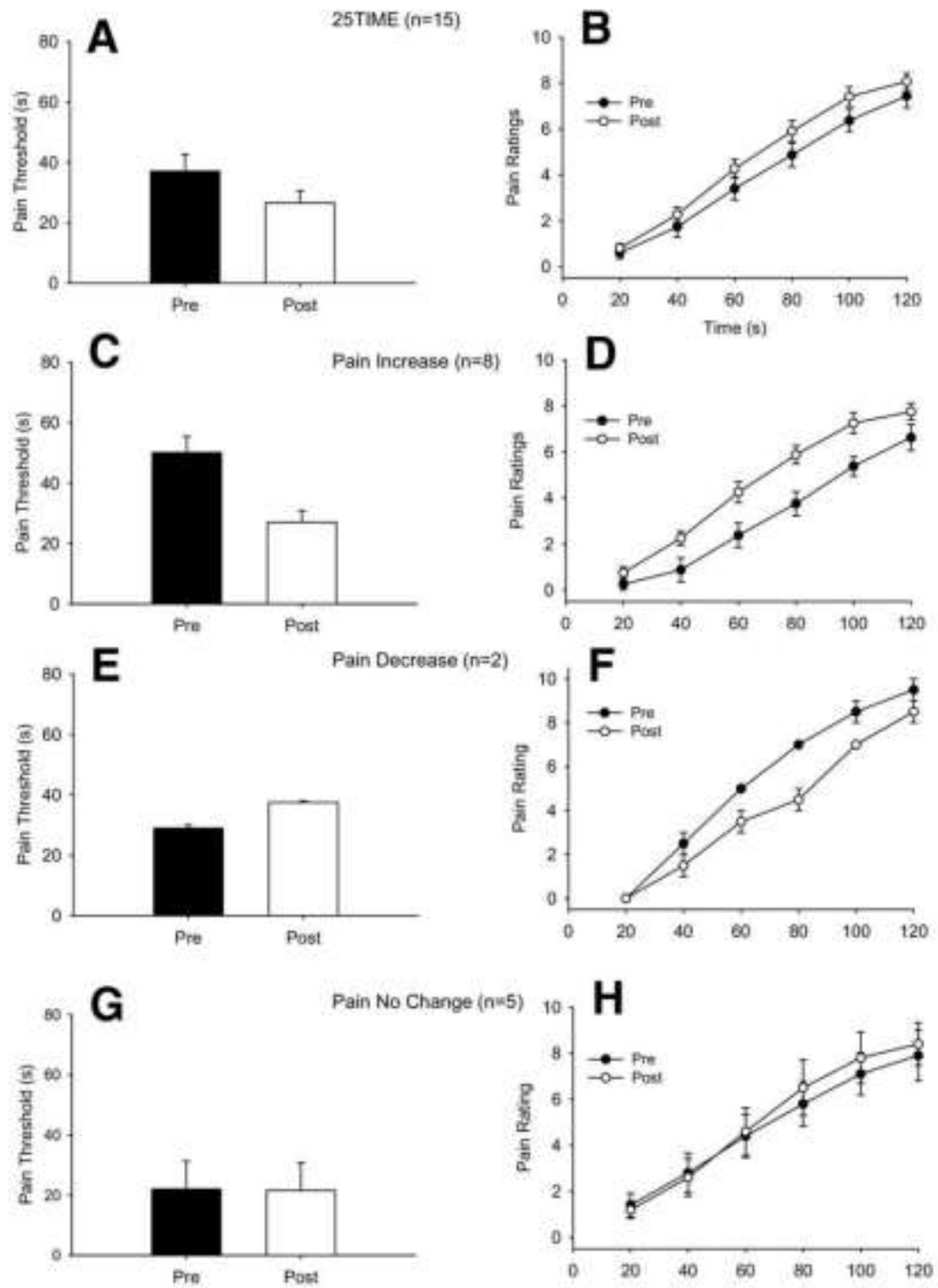

(A) Pain threshold and (B) pain ratings before (pre) and after (post) 25TIME. There was no significant difference in pain threshold or pain ratings after the isometric contraction $(P>.05)$. Based on the pain response, the subjects were divided into 3 groups (pain increase $[C, D]$, pain decrease $[E, F]$, and no change in pain $[\mathrm{G}, \mathrm{H}])$. There was a significant interaction between trial and pain response for pain ratings $(P<.05)$ but not for pain threshold $(P>.05)$. Data are represented as the average \pm standard error of the mean.

Archives of Physical Medicine and Rehabilitation, Vol. 92, No. 1 (January 2011): pg. 89-95. DOI. This article is (C) Elsevier (WB Saunders) and permission has been granted for this version to appear in e-Publications@Marquette. Elsevier (WB Saunders) does not grant permission for this article to be further copied/distributed or hosted elsewhere without the express permission from Elsevier (WB Saunders). 
Fig. 3
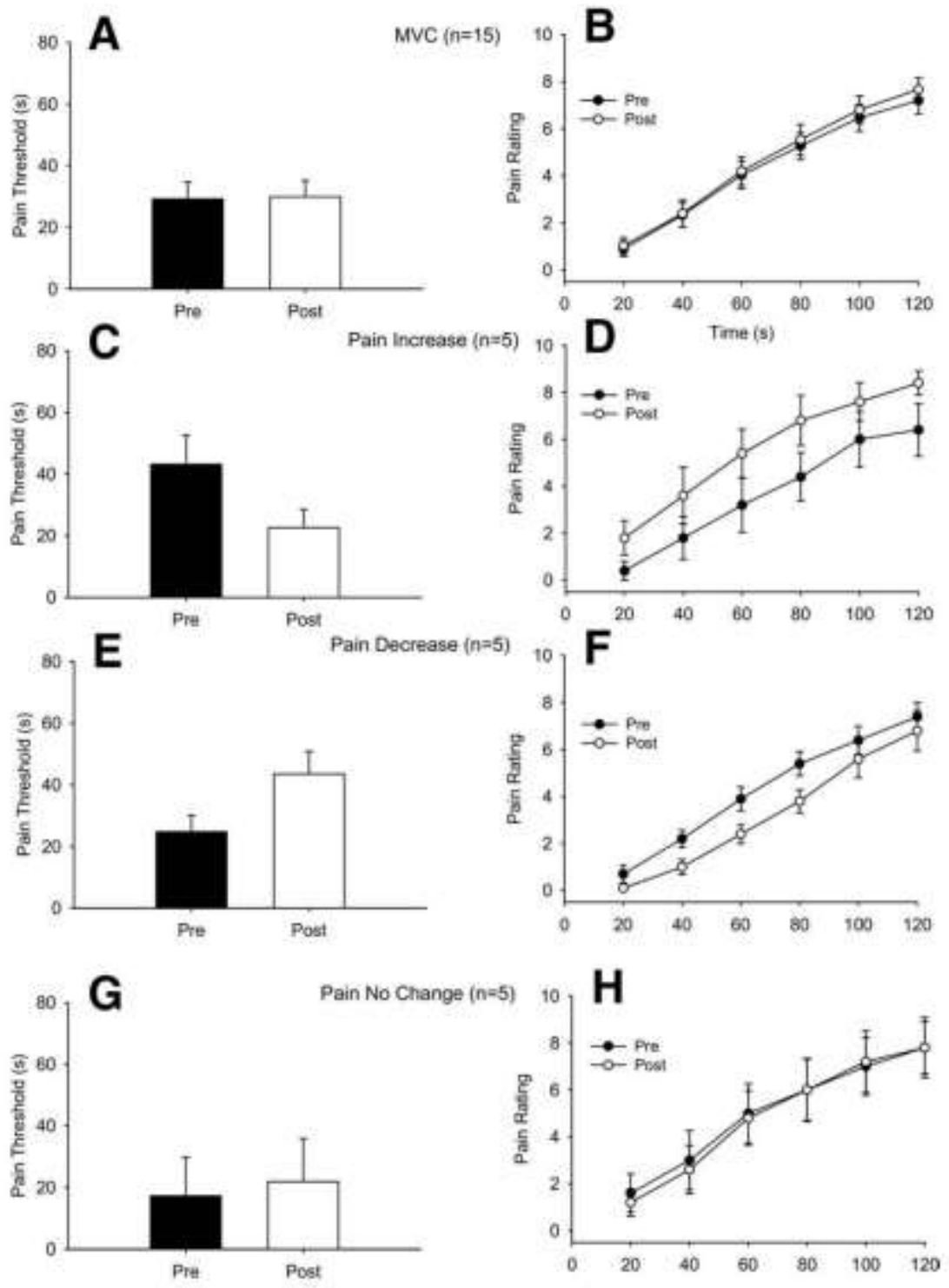

(A) Pain threshold and (B) pain ratings before (pre) and after (post) 3 brief MVCs. There was no significant difference $(P>.05)$ in pain threshold or pain ratings after the isometric contractions. Based on the pain response, the subjects were divided into 3 groups (pain increase $[C, D]$, pain decrease $[E$, $F]$, and no change in pain $[\mathrm{G}, \mathrm{H}]$ ). There was a significant interaction between trial and pain response for both pain threshold and pain ratings $(P<.05)$. Data are represented as the average \pm standard error of the mean.

Archives of Physical Medicine and Rehabilitation, Vol. 92, No. 1 (January 2011): pg. 89-95. DOI. This article is (C) Elsevier (WB Saunders) and permission has been granted for this version to appear in e-Publications@Marquette. Elsevier (WB Saunders) does not grant permission for this article to be further copied/distributed or hosted elsewhere without the express permission from Elsevier (WB Saunders). 